\title{
MFM imaging of expanded austenite formed on 304 SS and CoCrMo alloys
}

\author{
O. Öztürk ${ }^{\mathrm{a}, *}$, M. Fidan $^{\text {a }}$, S. Mändl ${ }^{\text {b }}$ \\ a Department of Physics, Izmir Institute of Technology, Urla 35430, Izmir, Turkey

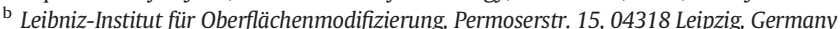

\section{A R T I C L E I N F O}

Available online 1 December 2013

\section{Keywords:}

CoCrMo alloy

Austenitic SS

Expanded austenite structure

PIII

Ferromagnetism

MFM

\begin{abstract}
A B S T R A C T
New data related to the magnetic nature of the expanded austenite layers on CoCrMo and austenitic stainless steel by nitrogen plasma immersion ion implantation (PIII) are presented. Implantations were performed in the temperature range between 300 and $550^{\circ} \mathrm{C}$ for a fixed processing time of $1 \mathrm{~h}$. Magnetic properties, nitrogen distribution, implanted layer phases, and surface topography were studied with a combination of experimental techniques involving magnetic force microscopy, SIMS, XRD, SEM and AFM. As a function of the processing temperature, phase evolution stage for both alloys follows the same trend: (1) initial stage of the expanded phase formation, $\gamma_{\mathrm{N}}$; (2) its full development; and (3) its decomposition into $\mathrm{CrN}$ precipitates and the $\mathrm{Cr}$-depleted matrix, fcc $\gamma$-(Co, Mo) for CoCrMo and bcc $\alpha$-(Fe, Ni) for 304 SS. MFM imaging reveals distinct, stripe-like ferromagnetic domains for the fully developed expanded austenite layers both on CoCrMo and 304 SS alloys. Weak domain structures are observed for the CoCrMo samples treated at low and high processing temperatures. The images also provide strong evidence for grain orientation dependence of magnetic properties. The ferromagnetic state for the $\gamma_{\mathrm{N}}$ phase observed here is mainly linked to large lattice expansions due to high $\mathrm{N}$ content.
\end{abstract}

(c) 2013 Elsevier B.V. All rights reserved.

\section{Introduction}

Ion beam surface modification methods can be used to create hard and wear resistant surface layers with enhanced corrosion resistance on austenitic stainless steels (SS) and $\mathrm{CoCr}$ base alloys using nitrogen ions [1-18]. This is mainly due to the formation of a metastable, high $\mathrm{N}$ content phase, $\gamma_{\mathrm{N}}$, at relatively low substrate temperatures from about 350 to $450{ }^{\circ} \mathrm{C}$. This surface layer is known as an expanded austenite layer. Different $\mathrm{N}$ contents and diffusion rates depending on grain orientation as well as anisotropic lattice expansion and high residual stresses are some peculiar properties associated with the formation of this phase $[3,4]$. Another peculiar feature of the expanded austenite phase is related to its magnetic character: the expanded phase/layer is found to have ferromagnetic as well as paramagnetic characteristics depending on its $\mathrm{N}$ contents (20-30 at.\%) and associated lattice expansions (as high as $10 \%$ ).

The magnetic nature of the expanded phase was first reported by Ichii et al. in 1986. This study [2], involving low temperature nitriding of $304 \mathrm{SS}$ at $400{ }^{\circ} \mathrm{C}$, found that the nitrided layer was composed of the $\gamma_{\mathrm{N}}$ phase (the term they used was S-Phase) and was of ferromagnetic nature. A much later study [4] involving low-energy, high-flux $\mathrm{N}$ implantation of $304 \mathrm{SS}$ at $400{ }^{\circ} \mathrm{C}$ revealed more details about the magnetic

\footnotetext{
* Corresponding author. Tel.: +90232 750 7708; fax: +902327507707.

E-mail address: orhanozturk@iyte.edu.tr (0. Öztürk).
}

nature of the $\gamma_{N}$ phase. Through Mössbauer spectroscopy and MOKE this investigation found the expanded phase to be ferromagnetically soft in nature, and to be distributed in the highest concentration region of the implanted layer. The $\gamma_{\mathrm{N}}$ phase transforms to the paramagnetic state deeper into the layer as the $\mathrm{N}$ content and associated lattice expansion decreased. That study [4] suggested that the ferromagnetic $\gamma_{\mathrm{N}}$ phase is achieved above a certain threshold of $\mathrm{N}$ content (above about 20 at.\%). Two recent studies, involving ion and gas-phase nitrided 316 stainless steels $[19,20]$, however, find a lower threshold $\mathrm{N}$ content value, about 14 at.\%, for the ferromagnetic expanded phase. After the detailed study [4], a number of publications reported observations related to the magnetic character of the $\gamma_{\mathrm{N}}$ phase formed on austenitic SSs [21-25]. More recently, the ferromagnetic nature of the $\gamma_{N}$ phase in austenitic SS alloys was revealed through the observation of stripe-like domains via magnetic force microscopy (MFM) imaging and through the observation of hysteresis loops via magneto-optic Kerr effect (MOKE) $[23,24]$. In these studies, the origin of the ferromagnetism in the $\gamma_{\mathrm{N}}$ phase is mainly explained by large lattice expansions (due to high $\mathrm{N}$ content), and should eventually be related to the underlying origins of magnetic effect in fcc-Fe and related alloys. Other researchers link the ferromagnetism of the $\gamma_{\mathrm{N}}$ phase to various defects (stacking faults, twins, etc.) observed in the expanded phase layers [26].

While, according to the literature of the last twenty years, there has been considerable research related to the expanded austenite phase in $\mathrm{CoCr}$ based alloys (the expanded phase in CoCrMo alloy was first reported by Wei et al. in 2004 [11]), there is only one study related to the magnetic nature of the $\gamma_{N}$ phase in this alloy system [27]. This study 
involving low temperature nitriding of $\mathrm{CoCrMo}$ alloy at $400{ }^{\circ} \mathrm{C}$ provided strong evidence for the ferromagnetic nature of the $\gamma_{\mathrm{N}}$ phase in this alloy through MFM observation of stripe domain structures as well as the hysteresis loops obtained through MOKE analysis.

Although the expanded phase itself has now been studied in detail by various research groups, its magnetic nature has been relegated to a minor role. Instead, the focus rather has been on mechanical, tribological, corrosion, and biocompatibility of expanded layers. However, there may be possible applications for magnetic $\gamma_{N}$ layers on non-magnetic substrates, underlying fcc $\gamma$ phases of austenitic SS and CoCrMo alloys have paramagnetic properties at room temperature. Two possible application areas that may utilize the magnetism of the expanded phase may be magnetic recording [28] and magnetic separation (very localized zone for trapping magnetic particles) [25]. On the other hand, the ferromagnetism of the expanded phase is probably unwelcome for biomedical SSs and $\mathrm{CoCr}$ based alloys, particularly from the view point of magnetic resonance imaging (i.e., MR compatibility).

The objective of this research is to present new data related to the magnetic nature of the expanded austenite layer/phase formed on CoCrMo and 304 SS alloys by nitrogen plasma immersion ion implantation (PIII). In this study, the magnetic behavior of the expanded phase layers will be mainly probed by magnetic force microscopy and supplemental data will be obtained by XRD, SEM, AFM, and SIMS.

\section{Experimental procedure}

Investigated materials were medical grade wrought low carbon CoCrMo (ISO 5832-12) and austenitic 304 SS alloys with base chemical compositions of $26 \% \mathrm{Cr}, 6 \% \mathrm{Mo}$, balance $\mathrm{Co}$, and $18 \% \mathrm{Cr}$, $8 \% \mathrm{Ni}$, balance $\mathrm{Fe}$ (all in mass \%), respectively. The specimens, with a disk-like geometry (diameter $=15 \mathrm{~mm}$, thickness $=3 \mathrm{~mm}$ ), were mechanically polished to mirror-like finish with an RMS roughness less than $5 \mathrm{~nm}$ for both material surfaces. The polycrystalline grain size for 304 SS and CoCrMo alloys ranged from $\sim 25$ to $50 \mu \mathrm{m}$ and $\sim 5$ to $15 \mu \mathrm{m}$, respectively. Nitrogen PIII experiments were carried out in the temperature range between 300 and $550{ }^{\circ} \mathrm{C}$ for a fixed processing time of $1 \mathrm{~h}$. The PIII experiments were performed in a cylindrical vacuum chamber with a $2.45 \mathrm{GHz}$ ECR plasma source operating at $150 \mathrm{~W}$ and a base pressure lower than 10 ${ }^{-6} \mathrm{~Pa} .10 \mathrm{kV}$ high voltage pulses with a pulse length of $15 \mathrm{~ms}$ were applied to the samples. The temperature variation was achieved by adjusting the pulse repetition rates.

Phase analysis was investigated with X-ray diffraction in both $\theta / 2 \theta$ geometry and grazing incident (GIXRD) mode using Philips X'Pert $\mathrm{XRD}$ system with $\mathrm{Cu}-\mathrm{K} \alpha$ in the angular range from $30^{\circ}$ to $100^{\circ}$. Topography was studied by scanning electron microscopy (SEM) and atomic force microscopy (AFM). The N implanted layer thicknesses were measured by SEM on the polished sample cross-sections. Nitrogen distribution was measured by secondary ion mass spectroscopy (SIMS). Crosssectional SEM images and SIMS profiles are not presented in this study. Energy dispersive X-ray (EDX) analysis was also used to obtain supplemental nitrogen concentration data for the implanted layers. During EDX analysis, SEM was operated at primary electron beam energy of $20 \mathrm{keV}$ (accelerating voltage), with probing depth of the order of approximately $1 \mu \mathrm{m}$ in layers with predominantly $\mathrm{Fe} / \mathrm{Cr} / \mathrm{Ni}$ composition.

The magnetic structures of the sample surfaces were imaged with a scanning probe microscope (Veeco, Dimension 3100) in magnetic force mode (MFM). In this mode, the probe tip coated with a ferromagnetic film gives an image showing the variation in the magnetic force between the magnetized probe and magnetic stray field originating from the sample surface. MFM imaging was carried out on all $\mathrm{N}$ implanted CoCrMo samples except on the sample implanted at $300{ }^{\circ} \mathrm{C}$. In the case of 304 SS specimens, the imaging was performed only on the sample that was $\mathrm{N}$ implanted at $350{ }^{\circ} \mathrm{C}$. MFM imaging was also carried out on polished 304 SS and CoCrMo alloys.

\section{Results}

\subsection{XRD analysis}

Fig. 1 presents the XRD results for the substrate alloys for this investigation. The polished CoCrMo alloy structure consists of a mixture of predominant fcc lattice structure [i.e., fcc $\gamma$-(Co, $\mathrm{Cr}, \mathrm{Mo})$ ] and weak hcp crystal structure [hcp $\varepsilon-(\mathrm{Co}, \mathrm{Cr}, \mathrm{Mo})]$. Ref. [23] indicates that the hcp $\varepsilon$ phase is located, as thin bands, within the fcc $\gamma$ matrix. The polished 304 SS alloy has mainly fcc lattice structure [i.e., fcc $\gamma$ - $(\mathrm{Fe}, \mathrm{Cr}$, $\mathrm{Ni}$ ) phase]. The XRD data for the SS substrate indicates a weak shoulder peak just to the right of fcc $\gamma(111)$ peak. This peak (labeled as $\alpha^{\prime}$ ) is attributed to strain-induced martensite phase due to mechanical polishing. GIXRD analysis of this sample (inset in Fig. 1) clearly confirms this finding, and suggests that this phase is formed on the top surface layer ( 50-100 $\mathrm{nm})$.

Fig. 2 shows the XRD patterns of 304 SS alloy specimens that were $\mathrm{N}$ implanted at temperatures ranging from $300{ }^{\circ} \mathrm{C}$ to $550{ }^{\circ} \mathrm{C}$ for a fixed processing time of $1 \mathrm{~h}$. The lowest temperature $\left(300^{\circ} \mathrm{C}\right)$ treated SS sample clearly shows the formation of the expanded austenite phase, $\gamma_{\mathrm{N}}$. The lack of the substrate peaks in the XRD data for the sample implanted at $350{ }^{\circ} \mathrm{C}$ suggests a much thicker expanded layer (at least $4 \mu \mathrm{m}$ ) with higher $\mathrm{N}$ content compared to the sample implanted at $300{ }^{\circ} \mathrm{C}$. At the treatment temperature of $400{ }^{\circ} \mathrm{C}$, the expanded phase decomposition starts, and the XRD data indicates the formation of $\mathrm{CrN}$ (weak peaks at 2 theta positions of about $37.5^{\circ}, 43.6^{\circ}$ and $62.6^{\circ}$ ). This sample also has the expanded phase but its peaks are weaker and shifted to higher angles compared to the samples prepared at 300 and $350{ }^{\circ} \mathrm{C}$. As the treatment temperature exceeds $450{ }^{\circ} \mathrm{C}$, the expanded phase peak intensities decrease, $\mathrm{CrN}$ peaks become much more apparent, and the data clearly shows the presence of bcc $\alpha$-phase $[\alpha-(\mathrm{Fe}$, $\mathrm{Ni})]$. At the highest processing temperature $\left(550{ }^{\circ} \mathrm{C}\right)$, the XRD pattern is mainly composed of fcc $\gamma$-CrN and bcc $\alpha$-(Fe, Ni) phase structures.

Fig. 3 shows X-ray diffraction patterns of $\mathrm{N}$ implanted CoCrMo alloy samples for various processing temperatures. The XRD data looks identical for specimens processed at low temperatures $\left(300,350{ }^{\circ} \mathrm{C}\right)$. The peaks to the left of the substrate $\gamma(111)$ and $\gamma(200)$ peaks suggest formation of the expanded phase in this alloy system. The $\gamma_{\mathrm{N}}$ layers on CoCrMo samples at these processing temperatures are found to be significantly thinner compared to the $\gamma_{\mathrm{N}}$ layers on 304 SS. At the treatment temperature of $400{ }^{\circ} \mathrm{C}$, the expanded layer formation is complete and a much thicker layer is developed (no substrate peaks are visible, similar to $304 \mathrm{SS}$ at $350{ }^{\circ} \mathrm{C}$ ). At processing temperatures $450{ }^{\circ} \mathrm{C}$ and above, the expanded austenite is decomposing into $\mathrm{CrN}$ precipitates. The precipitation of $\mathrm{CrN}$ depletes the expanded austenite of chromium resulting in

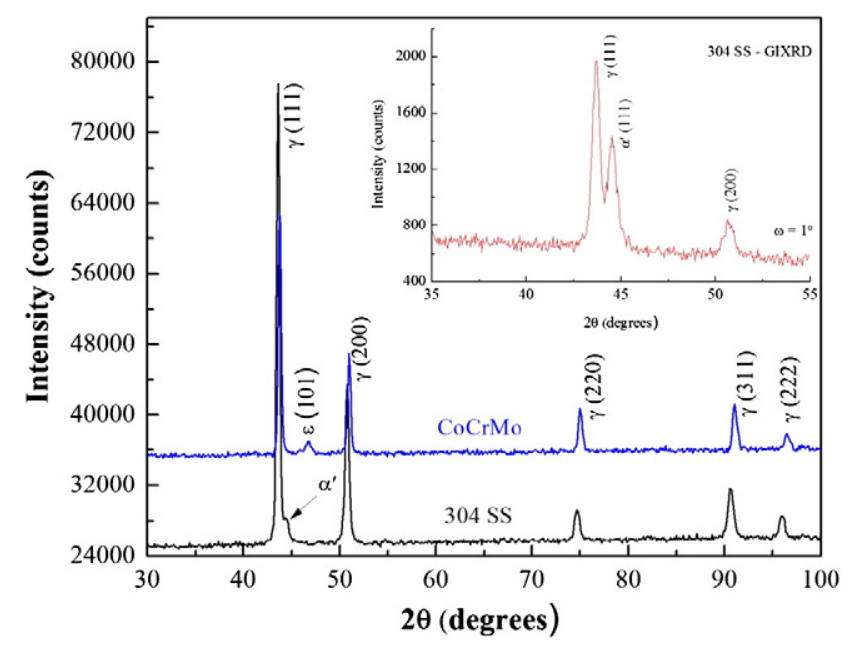

Fig. 1. XRD data for untreated 304 SS and CoCrMo substrate alloys. The inset is the GIXRD data for the 304 SS substrate alloy specimen. 


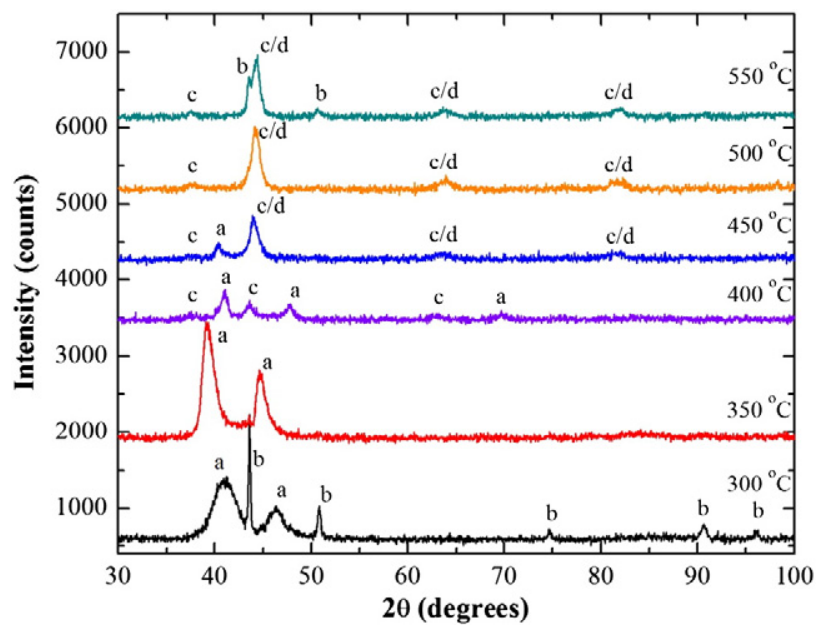

Fig. 2. XRD patterns for the $304 \mathrm{SS}$ specimens nitrogen PIII processed between $300{ }^{\circ} \mathrm{C}$ and $550{ }^{\circ} \mathrm{C}$ for a fixed time of $1 \mathrm{~h}$ : b - fcc substrate $\gamma$ phase, a - expanded phase $\gamma_{\mathrm{N}}, \mathrm{c}-\mathrm{CrN}$ precipitates, and $\mathrm{d}-\mathrm{bcc} \alpha$ phase, $\alpha-(\mathrm{Fe}, \mathrm{Ni})$.

the formation of a mixture of fcc $\gamma$-CrN and the substrate phase [i.e., fcc $\gamma$ - $\mathrm{Co}(\mathrm{Mo})]$. At the highest processing temperature of $550{ }^{\circ} \mathrm{C}$, this fcc phase is quite visible, albeit with a very low intensity and much broader than the original substrate peaks. The expanded layer peaks exist up to temperatures of $450{ }^{\circ} \mathrm{C}$, suggesting that at higher temperatures, the nitrogen containing layer is actually a mixture of $\mathrm{CrN}, \mathrm{Cr}_{2} \mathrm{~N}$ and the $\mathrm{Cr}$ depleted fcc phase. Tables 1 and 2 summarize the phase evolution stages (the expanded phase formation/development, its decomposition) as a function of processing temperature for both CoCrMo and 304 SS alloys. Formation of expanded austenite in austenitic stainless steels and $\mathrm{CoCr}$ alloys is already reported in scientific literature and not the primary focus of this study. Hence, effect of time and temperature on the expanded phase evolution can be found in Ref. [29]. Additionally, nitrogen content, diffusion and stress relaxation are also known to influence the results [15].

\subsection{Magnetic force microscopy imaging}

Magnetic force microscopy analysis was carried out on the surfaces of the polished and $\mathrm{N}$ implanted 304 SS and CoCrMo alloys. Figs. 4 and 5 show MFM imaging analysis results for all the $\mathrm{N}$ implanted CoCrMo samples except the sample implanted at $300{ }^{\circ} \mathrm{C}$. The MFM results for the $304 \mathrm{SS}$ sample that was $\mathrm{N}$ implanted at $350^{\circ} \mathrm{C}$ are shown in Fig. 6 .

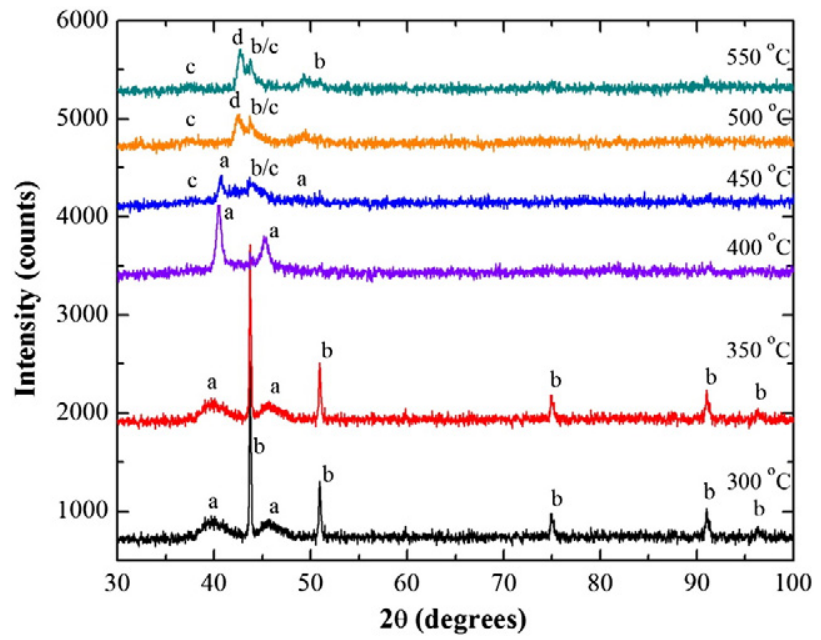

Fig. 3. XRD patterns for the CoCrMo alloy specimens nitrogen PIII processed between $300{ }^{\circ} \mathrm{C}$ and $550{ }^{\circ} \mathrm{C}$ for a fixed time of $1 \mathrm{~h}$ : b - fcc substrate $\gamma$ phase, a - expanded phase $\gamma_{\mathrm{N}}, \mathrm{c}-\mathrm{CrN}$ precipitates, and $\mathrm{d}-\mathrm{Cr}_{2} \mathrm{~N}$.
Table 1

Experimental results of nitrogen PIII into CoCrMo alloy samples. Predominant phases were determined from XRD. Magnetic structures were obtained via MFM imaging. The lattice expansion, $\Delta \mathrm{a} / \mathrm{a}=\left[\left\{\mathrm{a}\left(\gamma_{\mathrm{N}}\right)-\mathrm{a}(\gamma)\right\} / \mathrm{a}(\gamma)\right]$, refers to the relative difference in lattice spacing between fcc $\gamma$ substrate phase and fcc $\gamma_{\mathrm{N}}$ phase and it is an average value between (111) and (200) $\gamma-\gamma_{N}$ pair peaks. The root-mean-square roughness, RMS, was measured by AFM. The N implanted layer thicknesses were measured by SEM on the polished sample cross-sections and SIMS (values in parentheses). The $\mathrm{N}$ content values measured by EDX are listed in this table for completeness.

\begin{tabular}{|c|c|c|c|c|c|c|}
\hline $\begin{array}{l}\text { Temperature } \\
\left({ }^{\circ} \mathrm{C}\right)\end{array}$ & Phases & $\begin{array}{l}\text { Magnetic } \\
\text { structure }\end{array}$ & $\begin{array}{l}\Delta \mathrm{a} / \mathrm{a} \\
(\%)\end{array}$ & $\begin{array}{l}\text { Layer } \\
\text { Thickness } \\
(\mu \mathrm{m})\end{array}$ & $\begin{array}{l}\text { N content } \\
\text { (at.\%) }\end{array}$ & $\begin{array}{l}\text { RMS } \\
(\mathrm{nm})\end{array}$ \\
\hline Substrate & $\gamma, \varepsilon$ & Nonmagnetic $^{\mathrm{b}}$ & - & - & - & 1.5 \\
\hline 300 & $\gamma, \gamma_{\mathrm{N}}$ & $\begin{array}{l}\text { Weak } \\
\text { domains }\end{array}$ & 9.8 & $0.24(0.4)$ & 36 & 23 \\
\hline 350 & $\gamma, \gamma_{\mathrm{N}}$ & $\begin{array}{l}\text { Weak } \\
\text { domains }\end{array}$ & 9.8 & $0.48(0.8)$ & 38 & 36 \\
\hline 400 & $\gamma_{\mathrm{N}}$ & $\begin{array}{l}\text { Distinct } \\
\text { domains }{ }^{c}\end{array}$ & 9.9 & $2.55(3.0)$ & 34 & 75 \\
\hline 450 & $\begin{array}{l}\gamma, \gamma_{\mathrm{N}} \\
\mathrm{CrN}\end{array}$ & $\begin{array}{l}\text { Distinct } \\
\text { domains }\end{array}$ & 7.0 & $2.70(3.1)$ & 36 & 78 \\
\hline 500 & $\begin{array}{l}\gamma^{\mathrm{a}}, \mathrm{CrN}, \\
\mathrm{Cr}_{2} \mathrm{~N}\end{array}$ & $\begin{array}{l}\text { Weak } \\
\text { domains }\end{array}$ & 3.1 & $2.36(2.5)$ & 33 & 79 \\
\hline 550 & $\begin{array}{l}\gamma^{\mathrm{a}}, \mathrm{CrN} \\
\mathrm{Cr}_{2} \mathrm{~N}\end{array}$ & $\begin{array}{l}\text { Strong } \\
\text { domains }\end{array}$ & 2.5 & $2.10(2.4)$ & 31 & 78 \\
\hline
\end{tabular}

a $\gamma$ phase at 500 and $550{ }^{\circ} \mathrm{C}$ refers to fcc $\gamma$ - $(\mathrm{Co}, \mathrm{Mo})$ and is different than the substrate fcc $\gamma$-(Co, Cr, Mo) phase.

b CoCrMo substrate alloy is paramagnetic at room temperature.

c The ferromagnetism of the expanded phase layers is revealed through MFM imaging of stripe domains.

In these figures, the MFM images for the polished alloy surfaces are also presented. Distinct magnetic patterns are easily identified in certain regions of the MFM image taken on the surface of the polished SS alloy (Fig. 6). These are magnetic domains of the martensite that is the result of surface polishing process, as confirmed by both XRD and GIXRD. Parts of the image with no magnetic contrast probably belong to the untransformed paramagnetic austenite. On the other hand, it seems the polishing process does not modify the magnetic structure of the CoCrMo alloy since no magnetic contrast is observed in the MFM image of the polished surface of CoCrMo alloy (Fig. 4).

Figs. 4 and 5 display a series of MFM images clearly showing the evolution of the magnetic structure of the surface of $\mathrm{N}$ implanted CoCrMo

Table 2

Experimental results of nitrogen PIII into 304 SS alloy samples. Predominant phases were determined from XRD. Magnetic structures were obtained via MFM imaging. The lattice expansion, $\Delta \mathrm{a} / \mathrm{a}$, refers to the relative difference in lattice spacing between fcc $\gamma$ substrate phase and fcc $\gamma_{\mathrm{N}}$ phase and is given by $\Delta \mathrm{a} / \mathrm{a}=\left[\left\{\mathrm{a}\left(\gamma_{\mathrm{N}}\right)-\mathrm{a}(\gamma)\right\} / \mathrm{a}(\gamma)\right]$. The rootmean-square roughness, RMS, was measured by AFM. The N implanted layer thicknesses were measured by SEM on the polished sample cross-sections and SIMS profiles (values in parentheses). The $\mathrm{N}$ content values measured by EDX are listed in this table for completeness.

\begin{tabular}{|c|c|c|c|c|c|c|}
\hline $\begin{array}{l}\text { Temperature } \\
\left({ }^{\circ} \mathrm{C}\right)\end{array}$ & Phases & $\begin{array}{l}\text { Magnetic } \\
\text { structure }\end{array}$ & $\begin{array}{l}\Delta \mathrm{a} / \mathrm{a} \\
(\%)\end{array}$ & $\begin{array}{l}\text { Layer } \\
\text { thickness } \\
(\mu \mathrm{m})\end{array}$ & $\begin{array}{l}\text { N content } \\
\text { (at.\%) }\end{array}$ & $\begin{array}{l}\text { RMS } \\
(\mathrm{nm})\end{array}$ \\
\hline Substrate & $\gamma,{ }^{\mathrm{a}} \alpha^{\prime}$ & $\begin{array}{l}\text { Distinct } \\
\text { domains }\end{array}$ & - & - & - & 5 \\
\hline 300 & $\gamma, \gamma_{\mathrm{N}}$ & - & 7.5 & $1.1(1.0)$ & 35 & 24 \\
\hline 350 & $\gamma_{\mathrm{N}}$ & $\begin{array}{l}\text { Distinct } \\
\text { domains }\end{array}$ & 11.4 & $3.2(4.0)$ & 39 & 63 \\
\hline 400 & $\begin{array}{l}\gamma, \gamma_{\mathrm{N}} \\
\mathrm{CrN}\end{array}$ & & 6.2 & $10.1(9.0)$ & 36 & 52 \\
\hline 450 & $\begin{array}{l}\gamma_{\mathrm{N}}, \\
\mathrm{CrN}, \alpha\end{array}$ & & - & $11.5(12)$ & 29 & 54 \\
\hline 500 & $\begin{array}{l}\mathrm{CrN} \\
\alpha^{\mathrm{b}}\end{array}$ & & - & $14.9^{\mathrm{c}}$ & 25 & 41 \\
\hline 550 & $\begin{array}{l}\gamma, \mathrm{CrN}, \\
\alpha\end{array}$ & & 2.5 & $15.1^{\mathrm{C}}$ & 25 & 59 \\
\hline
\end{tabular}

a $\alpha^{\prime}$ is known as the martensite phase with bcc (or bct) lattice and is due to polishing; MFM image shows distinct ferromagnetic domains.

${ }^{b} \alpha$ phase has bcc structure and refers to bcc $\alpha$-(Fe, Ni).

c For these samples, SIMS has not been performed. 

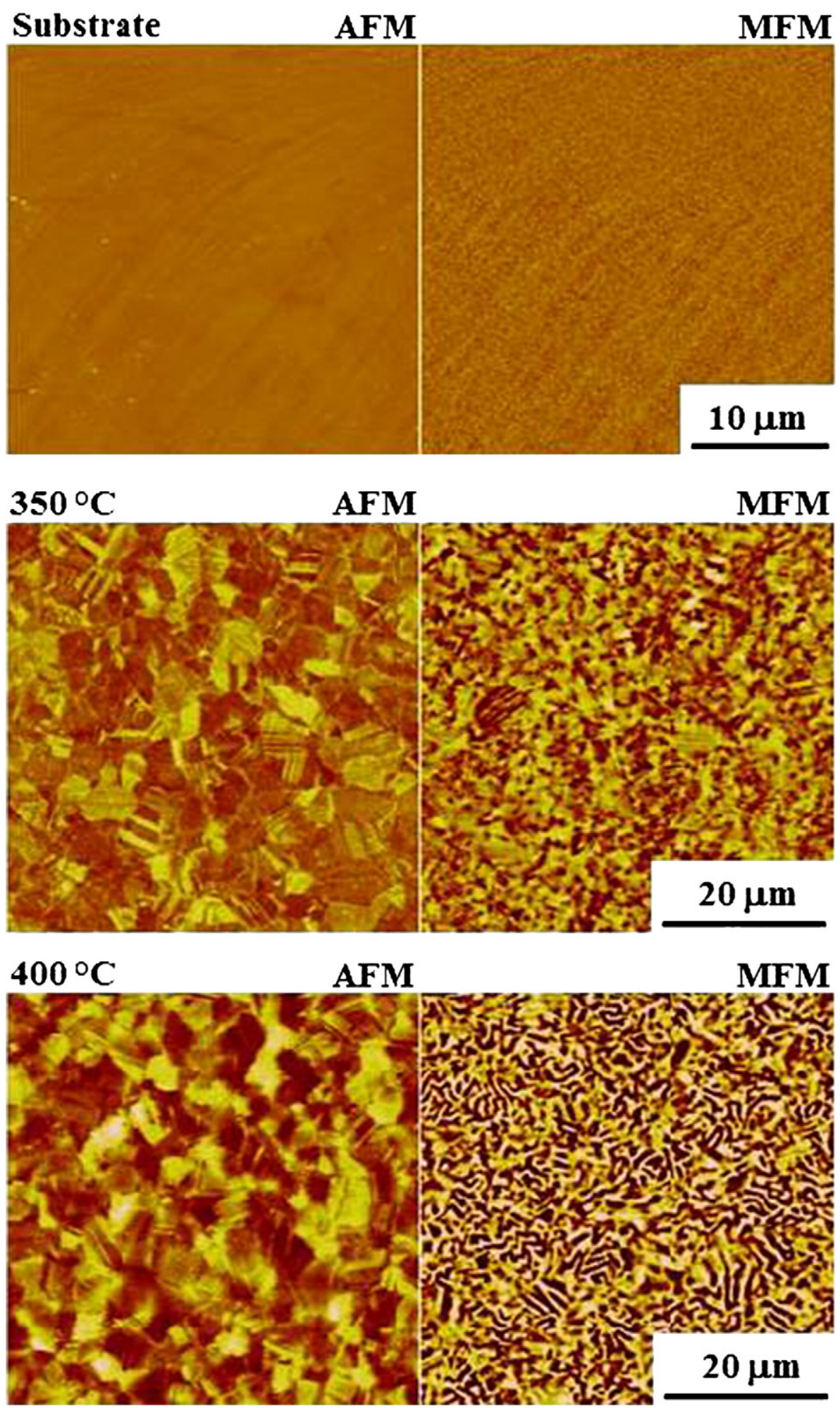

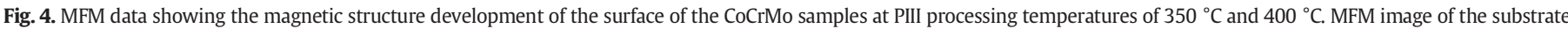

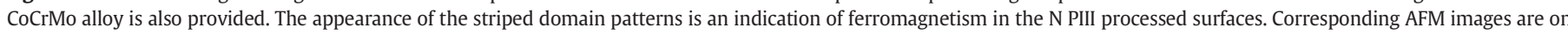
the left hand panel.

samples with increasing processing temperatures. The ferromagnetism for the $\mathrm{N}$ implanted CoCrMo surfaces becomes quite obvious through the observation of the striped domains, particularly for the samples treated at 400 and $450{ }^{\circ} \mathrm{C}$. The dark (light) stripe domain patterns observed in the MFM images are up (down) modulation of out-of-plane magnetization component, and they are often observed in a number of materials in thin film form. The magnetic domains in the MFM images exhibit different patterns from one grain to another. The domain morphology (i.e., size and shape) and the periodicity of domains even changes within a given grain.

Different domain patterns suggest different magnetic behaviors from grain-to-grain. For the surfaces treated at 400 and $450{ }^{\circ} \mathrm{C}$, this is probably attributed to different amounts of lattice expansion (due to different $\mathrm{N}$ contents) in the different grains as evidenced in the XRD 

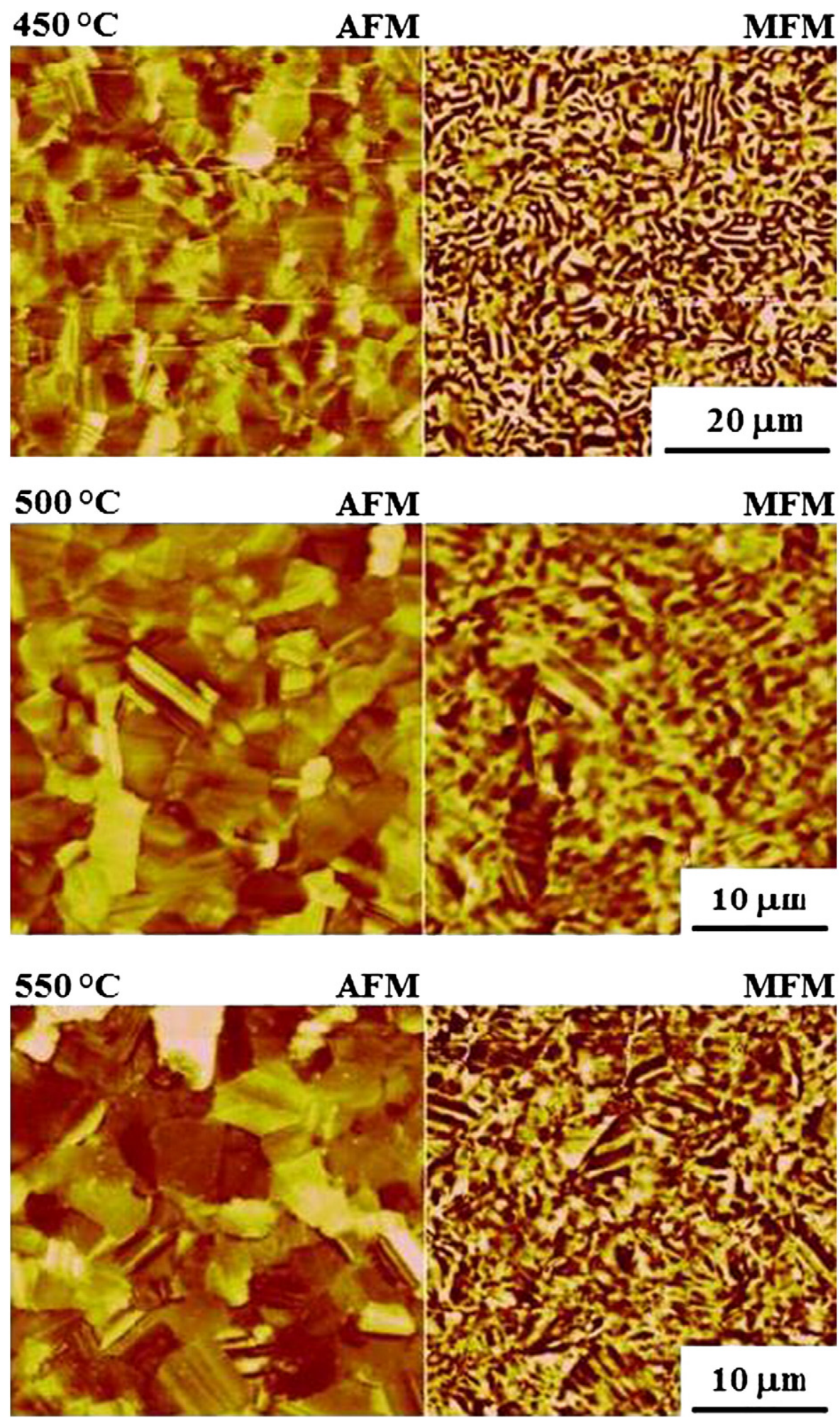

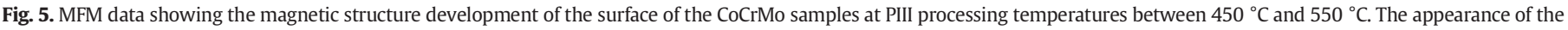
striped domain patterns is an indication of ferromagnetism in the N PIII processed surfaces. Corresponding AFM images are on the left hand panel.

results. According to the XRD data, the expanded phase is the dominant crystal structure in these surfaces, and the (200) $\gamma_{N}$ peak is shifted more than the (111) $\gamma_{\mathrm{N}}$ peak. The domain size/shape variations observed on the different grains may be due to the different intrinsic magnetic properties of the expanded phase in those grains. Although not carried out in this study, published papers $[19,24]$ have already established correlations between the domain structure and crystal orientation.
Although not as distinct and striped as those seen on the images of the surfaces at 400 and $450{ }^{\circ} \mathrm{C}$, the MFM images of the sample surfaces treated at 500 and $550{ }^{\circ} \mathrm{C}$ show domain patterns/structures. The domains are much more apparent for the sample surface treated at $550{ }^{\circ} \mathrm{C}$ compared to that at $500{ }^{\circ} \mathrm{C}$ although their XRD patterns are nearly identical. It is also clear from the MFM images that some grains show no magnetic contrast. This may be due to either an in-plane 
Substrate

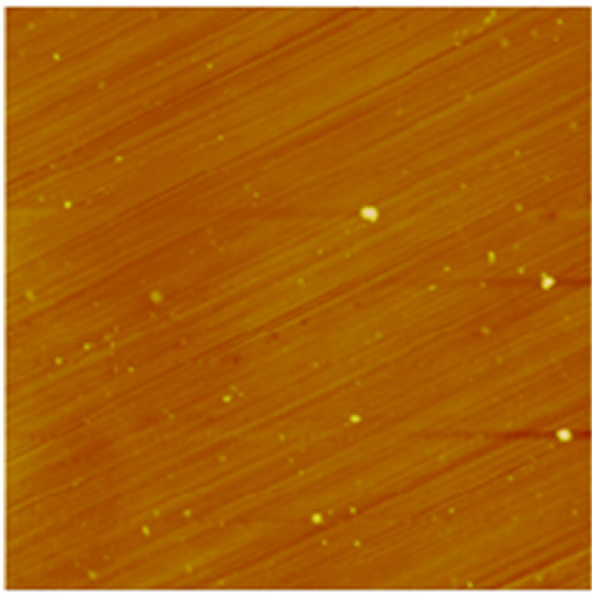

$350{ }^{\circ} \mathrm{C}$

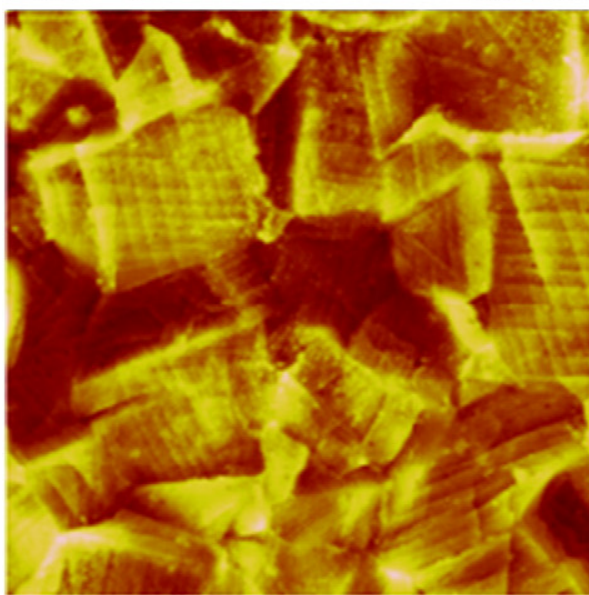

AFM

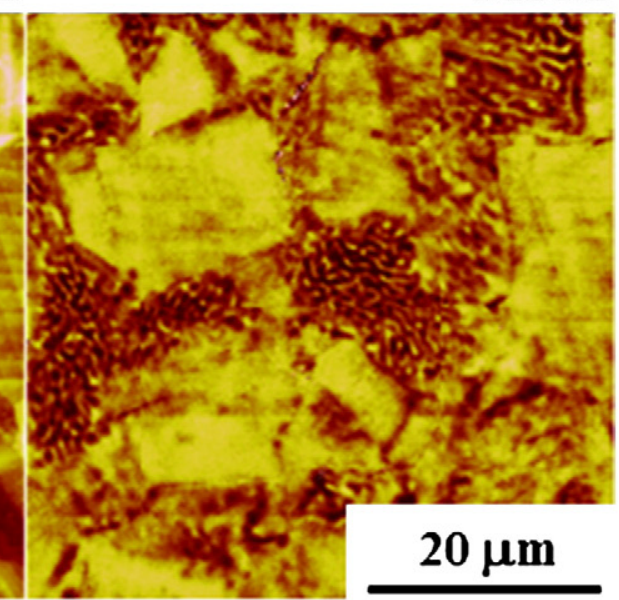

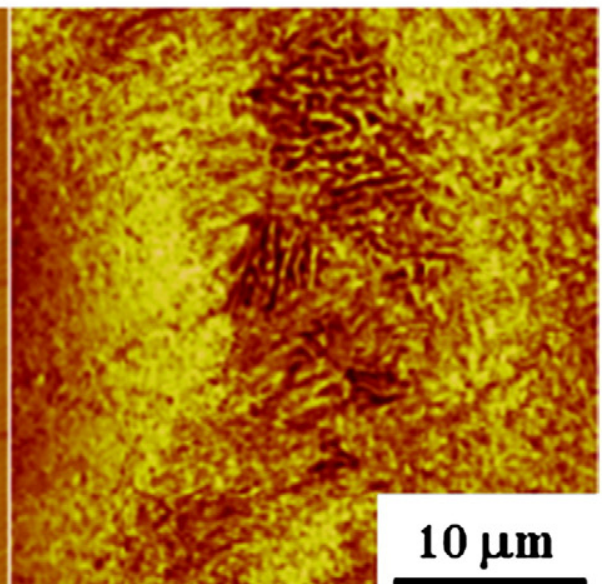

MFM

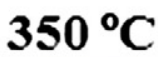

AFM
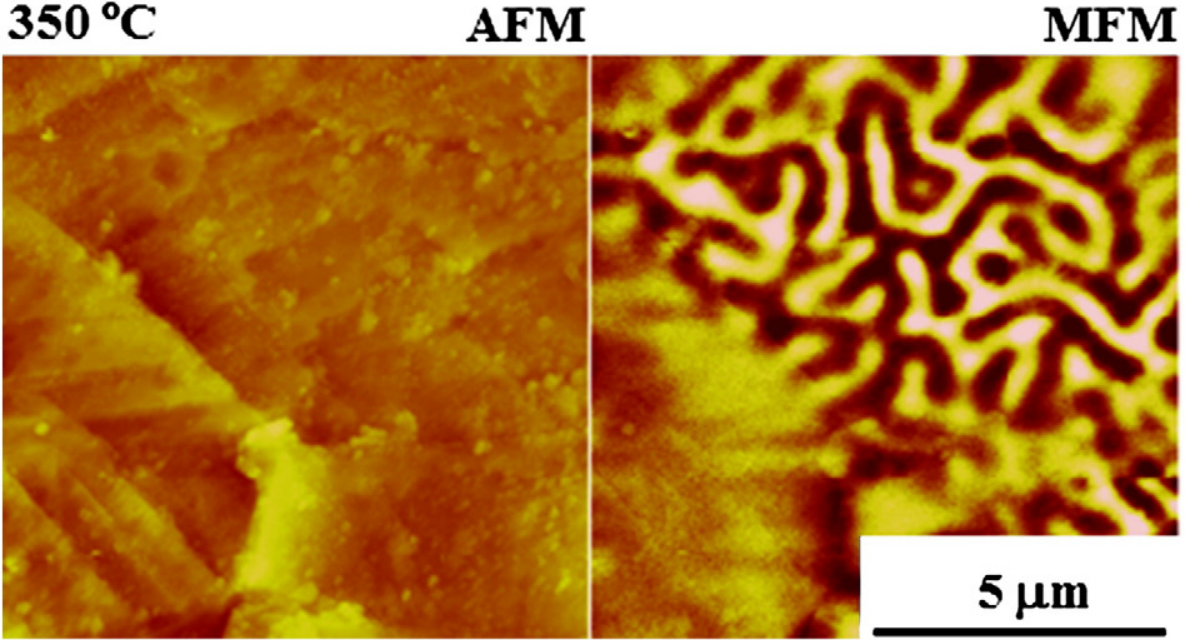

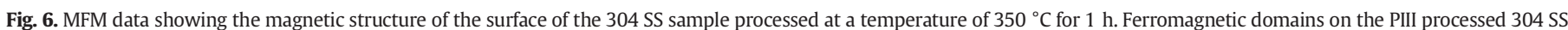

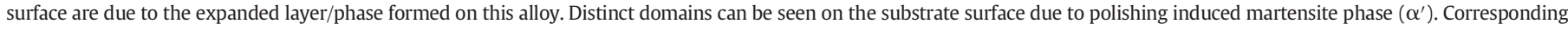
AFM images are on the left hand panel.

magnetization component or the expanded phase with less lattice expansion (lower $\mathrm{N}$ contents) (i.e., the paramagnetic $\gamma_{\mathrm{N}}$ phase). The latter seems more plausible since the XRD data for these samples show the expanded phase decomposing into $\mathrm{CrN}$ precipitates and the $\mathrm{Cr}$-depleted matrix, fcc $\gamma$-Co(Mo).

As mentioned above, MFM analysis was also carried out on the $\mathrm{N}$ implanted surfaces of 304 SS. Fig. 6 shows an MFM image taken on the surface of the sample implanted at $350{ }^{\circ} \mathrm{C}$. Stripe-like domains are quite visible in parts of the image suggestive of ferromagnetism for the $\mathrm{N}$ implanted layer. This is consistent with the XRD results which only show the expanded phase layer on this alloy at this temperature. For parts of the image in Fig. 6, there is no magnetic contrast, and this may be due to the paramagnetic $\gamma_{\mathrm{N}}$ or the magnetization lies in plane (stripe domains are typical of mostly out-of-plane magnetization). 
Imaging by MFM for the 304 surfaces treated at other temperatures was not performed in this study. However, it would be important to distinguish the ferromagnetism of the expanded phase/layer from those layers processed at higher temperatures. The XRD data for the $304 \mathrm{SS}$ sample treated at $550{ }^{\circ} \mathrm{C}$ shows $\mathrm{CrN}$ precipitates and the $\mathrm{Cr}$-depleted matrix of bcc $\alpha-(\mathrm{Fe}, \mathrm{Ni})$ as a consequence of the expanded phase layer decomposition. It would be interesting to investigate the surface of this sample using MFM since bcc $\alpha$ phase is known to be ferromagnetic.

\section{Discussion}

The application of nitrogen PIII to austenitic 304 SS and $\mathrm{CoCr}$ base alloys in the temperature range from 300 to $550{ }^{\circ} \mathrm{C}$ clearly demonstrates first the formation of an expanded austenite phase and then its decomposition in these materials. For both alloys, the phase evolution is as follows: (1) at low temperatures there is the expanded phase development stage; (2) at intermediate temperatures there is the completion of the expanded layer with a much thicker layer compared to the stage 1 ; and (3) at higher temperatures there is the decomposition of the expanded phase into a mixture of $\mathrm{CrN}+$ bcc $\alpha-(\mathrm{Fe}, \mathrm{Ni})$ matrix and $\mathrm{CrN}+$ fcc $\gamma$-(Co, Mo) for 304 SS and CoCrMo alloys, respectfully. However, in each stage, the onset temperature (transition temperature) is higher (about $50{ }^{\circ} \mathrm{C}$ ) for CoCrMo alloy compared to 304 SS. The new data presented here agrees quite well with previous $\mathrm{N}$ PIII studies of similar alloys [15,30,31] These investigations show that austenitic SS and $\mathrm{CoCr}$ alloys can be efficiently nitrided using PIII at temperatures ranging from 300 to $600{ }^{\circ} \mathrm{C}$ within a few hours. Further investigations show that for both alloys thermally activated diffusion (interstitial in nature) is observed but a much faster diffusion of nitrogen in SS compared to $\mathrm{CoCr}$ is obtained. This is also consistent with the layer thicknesses measured in this study (Table 1 ).

The most important finding in this study is related to the magnetic nature of the expanded austenite layer on CoCrMo alloy. The $\gamma \mathrm{N}$ phase/layer on CoCrMo is found to be ferromagnetic. The ferromagnetism is revealed through the observation of the stripe-like domains. The result is quite new and significant since, to the authors' knowledge, this is the second study to date reporting ferromagnetism for the expanded phase in this alloy system. The original study [27], which explored plasma nitriding of medical grade CoCrMo alloy with compositions similar to that used in the present work, found that the expanded phase/layer formed at $400{ }^{\circ} \mathrm{C}$ on this alloy has ferromagnetic properties as evidenced through the observation of stripe domains via MFM imaging and through hysteresis curves via MOKE. In comparison, there are quite a few studies reporting ferromagnetism for the $\gamma_{\mathrm{N}}$ phase/layer formed on austenitic stainless steels by various ion beam as well as gas nitriding processes [19].

In this and many other investigations, the ferromagnetism of the $\gamma_{\mathrm{N}}$ layers in austenitic SS and CoCrMo has been made clear through the stripe domain mapping by MFM imaging analysis [19-24]. MFM imaging is also carried out successfully on alloyed and unalloyed ferritic and/or dual phase stainless steels (DSS) as an alternative technique compared to destructive techniques such as chemical etching [32-34].

A careful investigation of MFM images and comparison with the XRD data suggest a good correlation between the magnetic structure development of the surfaces of the $\mathrm{N}$ implanted $\mathrm{CoCrMo}$ samples and the development and decomposition of the expanded phase/layers on them. For example, the MFM image of the surface of the CoCrMo sample implanted at $350{ }^{\circ} \mathrm{C}$ is composed of indistinct magnetic domains with weak magnetic contrast, while the imaging of the sample surface implanted at $400{ }^{\circ} \mathrm{C}$ reveals distinct, stripe domains with strong magnetic contrast. The XRD results show that at the treatment temperature of $400{ }^{\circ} \mathrm{C}$, the expanded layer formation is complete with much thicker layer in comparison to the less developed $\gamma_{\mathrm{N}}$ layer on the sample processed at $350{ }^{\circ} \mathrm{C}$. This correlation also holds true for the 304 SS specimen that was $\mathrm{N}$ implanted at $350{ }^{\circ} \mathrm{C}$ (MFM image containing stripe domains and XRD data indicating fully developed $\gamma_{\mathrm{N}}$ layer). The MFM image of the surface of the CoCrMo sample treated at $450{ }^{\circ} \mathrm{C}$ also shows distinct stripe domain structures. The XRD results for this sample suggest $\mathrm{CrN}$ precipitates within the expanded phase matrix. Apparently, the decomposed phase with precipitates in the sub-micrometer range still retains a memory of the original magnetic structure.

The MFM images in Figs. 4, 5 and 6 show that domain morphology (size and shape) changes from grain-to-grain and even within a grain. This is attributed to $\mathrm{N}$ content and lattice expansion variations in these grains as evidenced from the XRD data. Also, it is likely that the $\gamma_{\mathrm{N}}$ has different intrinsic magnetic properties in differently oriented grains. In this study, the relationship between crystal orientation and the domain structure (for example, through both MFM and EBSD) has not been carried out, but few such studies do exist in literature, particularly for the expanded phase layer on SS alloy [19,24,25]. There is no such study for the expanded phase layer on CoCrMo alloy. However, an alternative explanation involves plastic mechanical deformation due to the high stress values present in the expanded austenite layers. As dislocation lines are appearing at the surface within grains, exhibiting a regular, parallel spacing, an association of the domain boundaries within grains with these dislocation lines may be possible.

The ferromagnetic state for the $\gamma_{\mathrm{N}}$ phase/layers observed in this study is mainly linked to large lattice expansions ( $9 \%)$ due to high $\mathrm{N}$ contents ( 35 at.\%) [27]. As an interstitial impurity, nitrogen expands the host lattices of the stainless steel and CoCrMo alloy. At a more fundamental level, the origin of ferromagnetism in the $\gamma_{\mathrm{N}}$ phases comes from electronic structure of Fe (for stainless steel) or Co (for CoCrMo alloy) and more precisely from $3 \mathrm{~d}$ orbitals. Expanding the lattice reduces the $3 d-3 d$ overlap enhancing Fe or Co magnetic moments. A plausible explanation related to the ferromagnetism observed in the expanded austenite layer in 316 SS was recently given by Basso et al. [20]. The authors claimed that the most important effect governing the ferromagnetism is the $\mathrm{N}-\mathrm{Cr}$ interaction, which removes $\mathrm{Cr} 3 \mathrm{~d}$ electrons from the metal alloy valence band promoting ferromagnetism. An earlier study [26] suggested that both the lattice expansion and the defect density might be important for the magnetic properties of the expanded phase. This study indicated that fine changes in the atomic distances due to the stacking faults can induce paramagnetic to ferromagnetic transformation (the expanded phase normally contains a high density of dislocations, slip lines, deformation twins, and stacking faults).

\section{Conclusions and outlook}

In this research, new data related to magnetic nature of the expanded austenite layer/phase formed on austenitic stainless steel and CoCrMo alloys by nitrogen plasma immersion ion implantation is presented. The ferromagnetism of the expanded phase layers is revealed through MFM imaging analysis of stripe-like domain structures. Combined MFM imaging analysis and XRD data suggest a correlation exists between the magnetic structure development and the expanded phase development and decomposition stages. While distinct stripe domains with strong magnetic contrast are observed for the fully developed expanded phase layers on CoCrMo (also on 304 SS), indistinct domains with weak magnetic contrast are found for the expanded phase layer at earlier stages of its development (i.e. processing temperatures of $300,350{ }^{\circ} \mathrm{C}$ ) and at the stage where the expanded phase matrix is decomposing into $\mathrm{CrN}$ precipitates and the $\mathrm{Cr}$-depleted matrix, fcc $\gamma$-(Co, Mo) for CoCrMo alloy and $\mathrm{CrN}$ precipitates plus bcc $\alpha$-(Fe, $\mathrm{Ni}$ ). The MFM data presented suggests that the expanded phase magnetic behavior is changing with crystallographic orientation and this is consistent with lattice expansion and $\mathrm{N}$ content variations as evidenced from the XRD. 


\section{Acknowledgments}

The authors would like to thank TIPSAN for providing austenitic SS and CoCrMo alloy samples for this study. Departmental funding for acquiring MFM tips is appreciated.

\section{References}

[1] Z.L. Zhang, T. Bell, Surf. Eng. 1 (1985) 131.

[2] K. Ichii, K. Fujimura, T. Takase, Technol. Rep. Kansai Univ. 127 (1986) 134

[3] D.L. Williamson, O. Ozturk, R. Wei, P.J. Wilbur, Surf. Coat. Technol. 65 (1994) 15.

[4] O. Ozturk, D.L. Williamson, J. Appl. Phys. 77 (1995) 3839.

[5] G.A. Collins, R. Hutchings, K.T. Short, J. Tendys, M. Samandi, Surf. Coat. Technol. 74-75 (1995) 417.

[6] S. Parascandola, R. Günzel, R. Grötzshel, E. Richter, W. Möller, Nucl. Instrum. Methods Phys. Res. B 136-138 (1998) 1281

[7] J.P. Riviere, P. Meheust, J.P. Villain, C. Templier, M. Cahoreu, G. Abrasonis, L. Pranevicius, Surf. Coat. Technol. 158-159 (2002) 99.

[8] C. Blawert, B.L. Mordike, Y. Jiraskova, O. Schneeweiss, Surf. Coat. Technol. 116-119 (1999) 189.

[9] S. Mändl, B. Rauschenbach, J. Appl. Phys. 88 (2000) 3323.

[10] A. Martinavicius, G. Abrasonis, A.C. Scheinost, R. Donoix, F. Donoix, J.C. Stinville, G. Talut, C. Templier, O. Liedke, S. Gemming, W. Möller, Acta Mater. 60 (2012) 4065.

[11] B.R. Lanning, R. Wei, Surf. Coat. Technol. 186 (2004) 314.

[12] O. Öztürk, U. Türkan, A.E. Eroglu, Surf. Coat. Technol. 200 (2006) 5687.

[13] X.Y. Li, N. Habibi, T. Bell, H. Dong, Surf. Eng. 23 (2007) 45.

[14] J. Chen, X.Y. Li, T. Bell, H. Dong, Wear 264 (2008) 157.

[15] J. Lutz, J.W. Gerlach, S. Mändl, Phys. Status Solidi A 205 (2008) 980.

[16] L. Pichon, S. Okur, O. Öztürk, J.P. Riviere, M. Drouet, Surf. Coat. Technol. 204 (2010) 2913.
[17] A. Bazzoni, S. Mischler, N. Espallargas, Tribol. Lett. 49 (2013) 157.

[18] J. Buhagiar, H. Dong, J. Mater. Sci. Mater. Med. 23 (2012) 271-281.

[19] D. Wu, H. Kahn, G.M. Michal, F. Ernst, A.H. Heuer, Scripta Mater. 65 (2011) 1089.

[20] R.L.O. Basso, V.L. Pimental, S. Weber, G. Marcos, T. Czerwiec, I.J.R. Baumvol, C.A. Figueroa, J. Appl. Phys. 105 (2009) 124914.

[21] M.P. Fewell, D.R.G. Mitchell, J.M. Priest, K.T. Short, G.A. Collins, Surf. Coat. Technol. 131 (2000) 300.

[22] D.L. Williamson, P.J. Wilbur, F.R. Fickett, S. Parascandola, in: T. Bell, K. Akamatsu (Eds.), Stainless Steel 2000 - Proceedings of an International Current Status Seminar on Thermochemical Surface Engineering of Stainless Steels, The Institute of Materials, London, 2001, pp. 333-352.

[23] O. Öztürk, S. Okur, J.P. Riviere, Nucl. Instrum. Methods Phys. Res. B 8-9 (2009) 1540.

[24] E. Menendez, J.C. Stinville, C. Tromas, C. Templier, P. Villechaise, J.P. Riviere, M Drouet, A. Martinavicius, G. Abrasonis, J. Fassbender, M.D. Baro, J. Sort, J. Nogues, Appl. Phys. Lett. 96 (2010) 242509.

[25] E. Menendez, A. Martinavicius, M.O. Liedke, G. Abrasonis, J. Fassbander, J Sommerlatte, K. Nielsch, S. Surinach, M.D. Baro, J. Nogues, J. Sort, Acta Mater. 56 (2008) 4570.

[26] C. Blawert, H. Kalvelage, B.L. Mordike, G.A. Collins, K.T. Short, Y. Jiraskova, O. Schneeweiss, Surf. Coat. Technol. 136 (2001) 181.

[27] O. Öztürk, S. Okur, L. Pichon, M.O. Liedke, J.P. Riviere, Surf. Coat. Technol. 205 (2011) 280.

[28] H. Sanda, M. Takai, S. Namba, A. Chayahara, M. Satou, Appl. Phys. A. 50 (1990) 573.

[29] D. Manova, C. Günther, A. Bergmann, S. Mändl, H. Neumann, B. Rauschenbach, Nucl. Instrum. Methods Phys. Res. B 307 (2013) 310.

[30] J. Lutz, A. Lehman, S. Mändl, Surf. Coat. Technol. 202 (2008) 3747.

[31] J. Lutz, S. Mändl, Surf. Coat. Technol. 204 (2010) 3043.

[32] A. Dias, M.S. Andrade, Appl. Surf. Sci. 161 (2000) 109.

[33] S.M. Gheno, F.S. Santos, S.E. Kuri, J. Appl. Phys. 103 (2008) 053906.

[34] L. Batista, U. Rabe, S. Hirsekorn, NDT\&E Int. 57 (2013) 58-68. 